HEFAT2014

$10^{\text {th }}$ International Conference on Heat Transfer, Fluid Mechanics and Thermodynamics

14 - 16 July 2014

Orlando, Florida

\title{
EFFECT OF XENON GAS AND FOILS ON A MULTI-FOIL INSULATION
}

\author{
Haim Y.*, Weiss Y. and Letan R. \\ *Author for correspondence \\ Department of Mechanical Engineering, Ben-Gurion University of the Negev, \\ Beer-Sheva 84105, \\ Israel, \\ E-mail: hayimye@bgu.ac.il
}

\begin{abstract}
The miniaturization of thermal installations has been also extended to compact insulations in processes maintained at low or high temperatures, and restricted to minimal heat losses or gains. The current investigation has been conducted experimentally and numerically, aiming to predict the performance of a multi-foil array, in which xenon gas is entrapped between steel foils, separated and supported by widely spaced ceramic particles. A parametric study of the effect of an increased number of foils, as compared to the experimental array, shows the preferred directions to design of such arrays. The performance of an array operated with xenon gas near-atmospheric pressure is compared to the performance of arrays filled with other gases. The low thermal conductivity of xenon gas leads to a lower effective conductivity of the array, as compared to arrays operated with other gases. The equations of conduction and radiation are solved numerically for a wide range of pressures and temperatures. Good agreement with experimental results is achieved.
\end{abstract}

\section{INTRODUCTION}

Compact thermal insulations are needed for a variety of thermal management applications. Multi-Foil-Insulation (MFI) has been known as a very effective, compact technique. It was developed in the late sixties $[1,2,3]$, demonstrating an effective thermal conductivity of about $5 \times 10^{-4} \mathrm{~W} / \mathrm{m} \mathrm{K}$ in vacuum of 0.1 $\mathrm{Pa}$. That related to a gradient of hundred degrees, achieved in an insulation of a few millimeters. Its effective thermal conductivity is highly dependent upon the gas type and pressure. In vacuum its effective thermal conductivity is much lower than in conventional thermal insulations.

Multi-foil insulation is composed of multiple metallic plates or shells, separated by ceramic spacers. The plates or shells are usually referred to as "shields", being reflective, and made of high-melting metals. The ceramic spacers are oxide particles. They provide support for the foils, and prevent them from touching each other. The spacers are applied to one side of a foil, which is usually a long strip wrapped spirally around a device of any configuration.

Models for this type of insulation are generally related to radiation between the shields, conduction in the entrapped gas and to conduction across the particles. Keller et al. [4] studied high-temperature multi-layer insulation performance in a changing environment. He analyzed the dependence of heat transfer modes on various design parameters, by illustrating examples, like a probe for solar system exploration or a solar space power system.

\section{NOMENCLATURE}

\begin{tabular}{|c|c|c|}
\hline $\mathrm{Kn}$ & & Koudc o numb \\
\hline $\mathrm{k}$ & {$[\mathrm{W} / \mathrm{m} \mathrm{K}]$} & Thermal conductivity \\
\hline $\mathrm{k}_{0}$ & {$[\mathrm{~W} / \mathrm{m} \mathrm{K}]$} & $\begin{array}{l}\text { Thermal conductivity of the gas at atmospheric } \\
\text { pressure and specified temperature }\end{array}$ \\
\hline $\mathrm{L}$ & [m] & The length of the shield (cylinder) \\
\hline $\mathrm{Lc}$ & {$[\mathrm{m}]$} & the characteristic dimension \\
\hline $\mathrm{P}$ & [Pa] & Pressure \\
\hline $\operatorname{Pr}$ & {$[-]$} & Prantl number \\
\hline $\mathrm{q}$ & {$[\mathrm{W}]$} & Rate of heat transfer \\
\hline q' & [W/m] & Rate of heat transfer per unit length \\
\hline q" & [W/m2] & Rate of heat transfer per unit area \\
\hline $\mathrm{R}$ & {$[\mathrm{K} / \mathrm{W}]$} & Thermal resistance \\
\hline $\mathrm{r}$ & {$[\mathrm{m}]$} & Radius \\
\hline $\mathrm{T}$ & {$\left[\mathrm{K}\right.$ or $\left.{ }^{\circ} \mathrm{C}\right]$} & Temperature \\
\hline th & {$[\mathrm{m}]$} & Thickness \\
\hline \multicolumn{3}{|c|}{ Greek symbols } \\
\hline \multicolumn{2}{|c|}{$\alpha$} & Accommodation coefficient \\
\hline \multicolumn{2}{|l|}{$\beta$} & Constant $\quad \beta=\frac{2}{\gamma+1} \frac{\gamma}{\operatorname{Pr}} \frac{2-\alpha}{\alpha}$ \\
\hline$\gamma$ & \multirow{4}{*}{ [m] } & Specific heat ratio \\
\hline$\lambda$ & & Mean free path \\
\hline$\sigma$ & & Stephan-Boltzmann constant \\
\hline$\varepsilon$ & & Surface emissivity \\
\hline \multicolumn{3}{|c|}{ Subscripts } \\
\hline av & & Average \\
\hline $\mathrm{c}$ & & Cold \\
\hline $\mathrm{e}$ & & Effective \\
\hline $\exp$ & & Experimental \\
\hline $\mathrm{g}$ & & Gaseous \\
\hline $\mathrm{h}$ & & Hot \\
\hline in, $\mathrm{i}$ & & In \\
\hline $\mathrm{j}$ & & Index \\
\hline out, o & & Out \\
\hline $\mathrm{p}$ & & Particles \\
\hline $\mathrm{r}$ & & Radiative \\
\hline sh & & Shield \\
\hline th & & Thermal \\
\hline
\end{tabular}

Kang et al. [5] investigated steady-state heat transfer across a radial configuration of a multi-foil insulation. A model was 
presented for conduction through the gas, and for thermal radiation between shields. Conduction through the spacer zirconia particles was neglected. Stauffer et al. [6] studied the effective thermal conductivity of multi-foil insulation as a function of temperature and pressure. The authors developed a model for the multi-layer array, which consisted of thin metallic foils held apart by tiny ceramic particles. The radiation and gas conduction models were compared to data in the literature, while for conduction in the spacers an empirical correlation was developed. Some of their postulations were that foils are isothermal and gray, tunneling effects are negligible, free convection in the gas is negligible, and the ceramic spacers do not interfere with the foil-to-foil radiation and the foil-to-foil gaseous conduction. The gas conduction in the gap is identified in four regimes, characterized by the Knudsen number [7]: continuum at $\mathrm{Kn}<0.01$, temperature-jump for $0.01<\mathrm{Kn}<0.1$, transition for $0.1<\mathrm{Kn}<10$, and free molecular regime at $\mathrm{Kn}>10$. In the present study the four regimes are covered by the physical model, the parametric analysis and the experiments. Convective heat transfer between the shields is negligible at Rayleigh numbers below 1700 [8].

In this study the performance of an array operated with xenon gas near-atmospheric pressure is compared to the performance of arrays filled with other gases. A parametric study was conducted for the number of foils and for the gap size.

\section{PHYSICAL MODEL}

The physical model and experimental apparatus [9] were used to predict the thermal performance of the insulation array with xenon as the interstitial gas, and for the parametric study.

The physical model was also verified in [9] with the experimental data of Kang et al. [5] in a cylindrical, radial, multi-foil array, in argon gas.

The physical model is aimed to predict the effective thermal conductivity of a cylindrical multi-foil insulation array in steady state. The model is based on conduction in spherical particles, which separate the foils, conduction in the entrapped gas in the internal space, radiation in the gap between the foils, and conduction across the foils, defined as shields. These mechanisms of heat transfer are presented in Figure 1, as an electrical analogy.

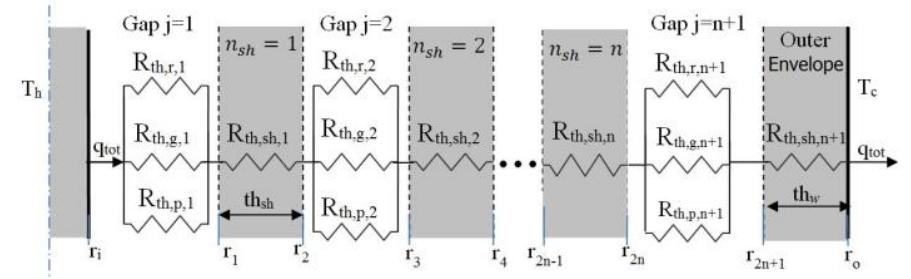

Figure 1 Electrical analogy of the heat transfer mechanism

The model is based on several assumptions: Heat is transferred only radially. The shields are coaxial, having uniform gaps between them. All the surfaces have the same emissivity, which is independent of temperature. The entrapped gas has no effect on radiation. The radiation between the shields is unobstructed by the particles. The gap between adjacent shields is wider than the minimal wave length, inhibiting radiation tunneling. Convective heat transfer is negligible in gap widths, which corresponds to Rayleigh numbers below 1700.

The radial heat transfer rate per unit length, by the gas, between any two adjacent shields, in all flow regimes e.g.: from the molecular to the continuum regime, is given by the following equation $[9,10,11]$ :

$$
q_{g, j}^{\prime}=\frac{q_{g, j}}{L}=\frac{2 \pi k_{0}\left(T_{2 j-2}-T_{2 j-1}\right)}{\ln \left(\frac{r_{2 j-1}}{r_{2 j-2}}\right)+\beta \lambda\left(\frac{1}{r_{2 j-1}}+\frac{1}{r_{2 j-2}}\right)}, j=1,2 \ldots n+1
$$

where $q_{g, j}$ is the radial heat transfer rate in the gas in gap $\mathrm{j}$ (Figure 1), $\mathrm{L}$ is the cylinder length, $r$ is the radius and $T$ is the temperature of the surface defined by index $j, k_{0}$ is the thermal conductivity of the gas at atmospheric pressure and at the specified temperature.

The effective conductivity was calibrated experimentally in vacuum to minimize gas conduction. Having finally the effective thermal conductivity of the particles, their conduction rate per unit length of the array, could be obtained between any two adjacent shields,

$$
q_{p, j}^{\prime}=\frac{2 \pi k_{p, e, j}\left(T_{2 j-2}-T_{2 j-1}\right)}{\ln \left(\frac{r_{2 j-1}}{r_{2 j-2}}\right)}, j=1,2 \ldots n+1
$$

where $r$ is the radius of the surface, $T$ is the temperature of the surface defined by the index $\mathrm{j}$ (Figure 1.), and $\mathrm{k}_{\mathrm{p}, \mathrm{e}}$ is the experimentally calibrated effective thermal conductivity of the particles.

The radiation rate between shields per unit length is expressed as,

$$
q_{r, j}^{\prime}=\frac{2 \pi r_{2 j-2} \varepsilon \sigma\left(T_{2 j-2}^{4}-T_{2 j-1}^{4}\right)}{2-\varepsilon}, j=1,2 \ldots n+1
$$

where, $\sigma$ is the Stephan Boltzman constant and $\varepsilon$ is the surface emissivity.

The total heat transfer rate per unit length of the array, between any two adjacent shields is,

$$
q^{\prime}=q_{s h, j}^{\prime}=q_{j}^{\prime}=q_{p, j}^{\prime}+q_{g, j}^{\prime}+q_{r, j}^{\prime}
$$

The effective radial thermal conductivity of the insulation array, $k_{e}$, is then the following,

$$
k_{e}=\frac{q^{\prime} \ln \left(\frac{r_{o}}{r_{i}}\right)}{2 \pi\left(T_{\text {in }}-T_{\text {out }}\right)}
$$

where $r_{o}$ and $r_{i}$ are the outer and inner radii respectively, $T_{i n}$ and $T_{\text {out }}$ are the inner (hot) and outer (cold) temperatures respectively. 


\section{PARAMETRIC STUDY}

In this section a parametric study was conducted to examine the influence of various parameters on the effective thermal conductivity of the specific insulation array. The developed "shield to shield" numeric code, was built by using the Engineering Equation Solver (EES software) with all the builtin material physical properties. The parameters that define the experimental insulation array are:

The emissivity of the shields is $\varepsilon=0.2$. The number of the shields is $\mathrm{n}=40$. The gap between any adjacent shields is $50 \mu \mathrm{m}$ corresponding to the particles diameter. The inner and outer diameters of the insulation array are $\mathrm{r}_{\mathrm{i}}=0.0075 \mathrm{~m}$, and $r_{0}=0.01015 \mathrm{~m}$. The interstitial gas is xenon. The calibrated effective conductivity of the particles in the gap is $2.13 \times 10^{-4}$ $\mathrm{W} / \mathrm{m} \mathrm{K}$. The thickness of outer envelope is $\mathrm{th}_{\mathrm{o}}=120 \mu \mathrm{m}$. The shield thickness is $\mathrm{th}_{\mathrm{sh}}=12 \mu \mathrm{m}$. The effective thermal conductivity of the insulation array was calculated at constant hot and cold temperatures of $\mathrm{Th}=500{ }^{\circ} \mathrm{C}$ and $\mathrm{Tc}=50^{\circ} \mathrm{C}$.

In each case, only one parameter is being investigated while all the other parameters are held constant. The parameters investigated are: gas type, number of shields, and gap size between shields. The results are illustrated graphically. In all the figures the effective conductivity of the array is presented as a function of gas pressure.

\section{Gas type}

The developed model was used for calculation of the effective thermal conductivity of the array, while in the gap between the foils, helium, nitrogen [9], argon or xenon are entrapped. The effect of the gas type on the effective thermal conductivity of the insulation array with 40 shields in the pressure range of $0.01 \div 1 \times 10^{5} \mathrm{~Pa}$ is illustrated in Figure 2. Up to about $10 \mathrm{~Pa}$ each of the four entrapped gases provides the same conductivity of the array. In the range of $10-1,000 \mathrm{~Pa}$, xenon displays the lowest conductivity, while nitrogen brings about the highest. Above 1,000 $\mathrm{Pa}$, and in particular at atmospheric pressure, helium produces the highest conductivity of 0.25 $\mathrm{W} / \mathrm{m} \mathrm{K}$, while in xenon the conductivity of $0.01 \mathrm{~W} / \mathrm{m} \mathrm{K}$ is reached.

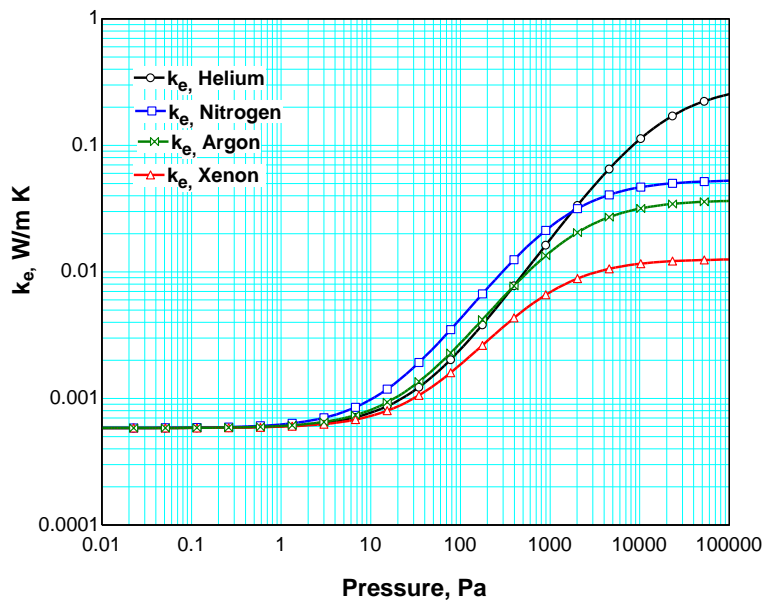

Figure 2 Effective thermal conductivity of the array as a function of pressure of helium, nitrogen [9], argon and xenon gases, in an array of 40 shields

\section{Number of shields}

The shields have two major roles: to reflect the electromagnetic radiation waves and to limit the distance travelled by the gas molecules. The first one is most important in vacuum, and at high temperatures, where thermal radiation is dominant. The other one is most important in reducing the gas conduction.

The influence of the number of shields on the effective thermal conductivity of the array, using nitrogen gas and gaps of $50 \mu \mathrm{m}$ is displayed in Figure 3, and using xenon gas in Figure 4 . The number of shields examined is, $\mathrm{n}=0,1,5,20$, 40, 200, for nitrogen and $n=0,1,5,20,200$ for xenon, in the pressure range of $0.01-1 \times 10^{5} \mathrm{~Pa}$ as shown in Figures 3,4, while Figure 3 (b) shows the conductivity variation within the range of $0.01-20 \mathrm{~Pa}$. At the low number of shields, namely $n=0-5$, the conductivity is high. It is reduced considerably as the number of shields increases, and the insulation thickness within the entire pressure range. The thickness of the external wall contributes to this effect. However, above 20 shields the contribution of the external wall is negligible. This effect was tested by running the model with the external wall thickness similar to that of the shields. And indeed conductivity of the array did not vary significantly with the number of shields exceeding 20. Some allowance has to be made for the larger external surface area.

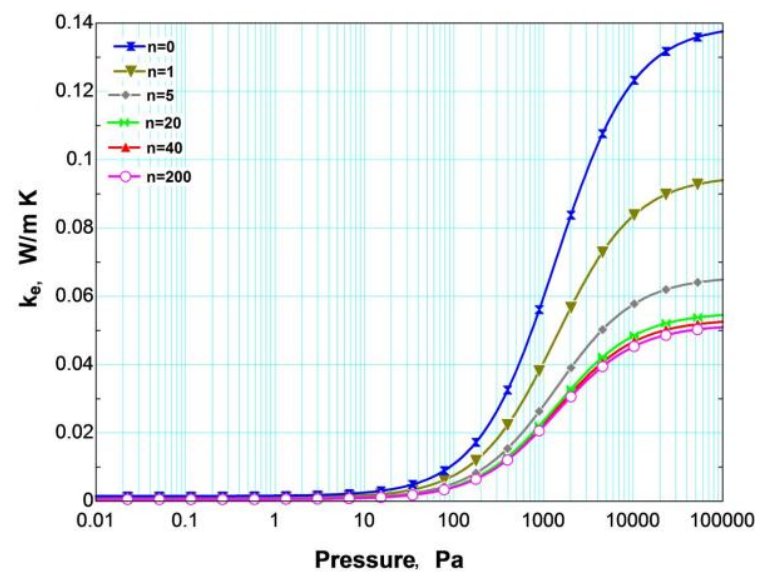

(a)

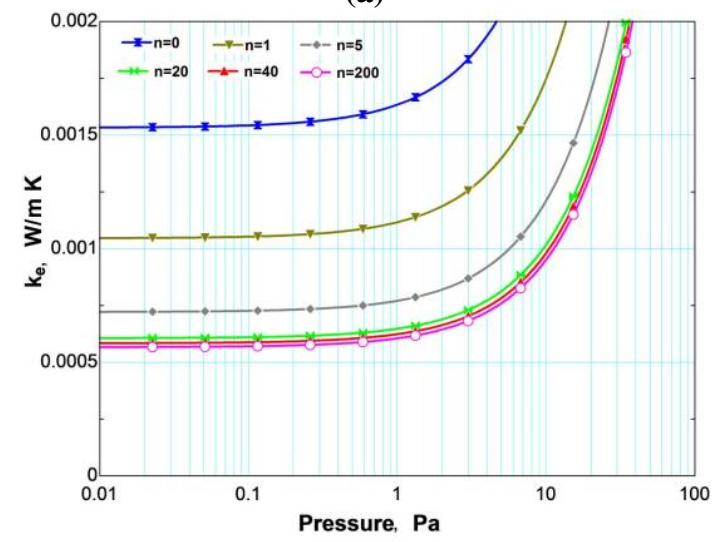

(b)

Figure 3 Effective thermal conductivity with different number of shields and as a function of nitrogen gas pressure. Gap

between shields $-50 \mu \mathrm{m}$. Nitrogen at $n=40$ [9]. (a) Pressure range $-0.01-1 \times 10^{5} \mathrm{~Pa}$. (b) Pressure range $-0.01-100 \mathrm{~Pa}$ 


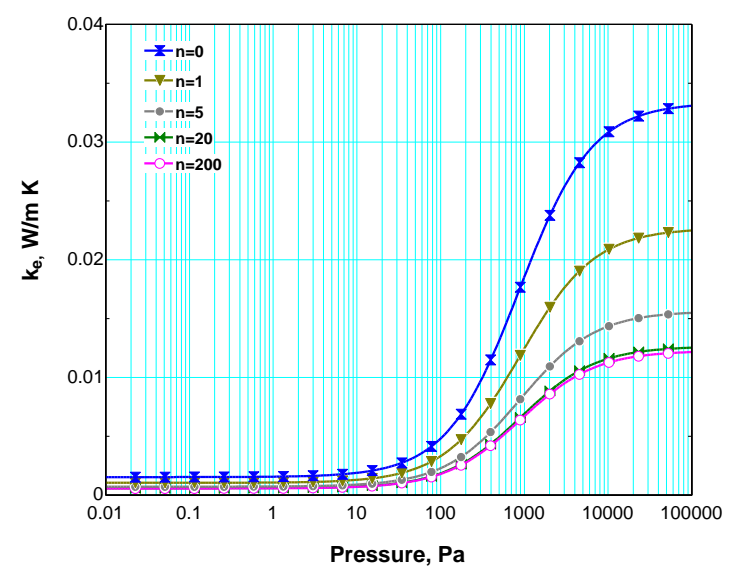

Figure 4 Effective thermal conductivity with different number of shields and as a function of xenon gas pressure

\section{Gap size}

The effect of gap size on the array conductivity at different xenon gas pressures is illustrated in Figure 5. The effect is shown at four pressures, $\mathrm{P}=1,10,50,100 \mathrm{~Pa}$. The gap size ranges from $1 \times 10^{-6} \mathrm{~m}$ to $1 \times 10^{-3} \mathrm{~m}$ in an array of 40 shields. At the smallest size of the gap, the array conductivity varies within $3.3 \times 10^{-3}-3.6 \times 10^{-3} \mathrm{~W} / \mathrm{m} \mathrm{K}$. As the gap is increased to about $2 \times 10^{-5} \mathrm{~m}$, the conductivity reaches its minimum, which varies with pressure of the gas. It is higher at higher pressures.

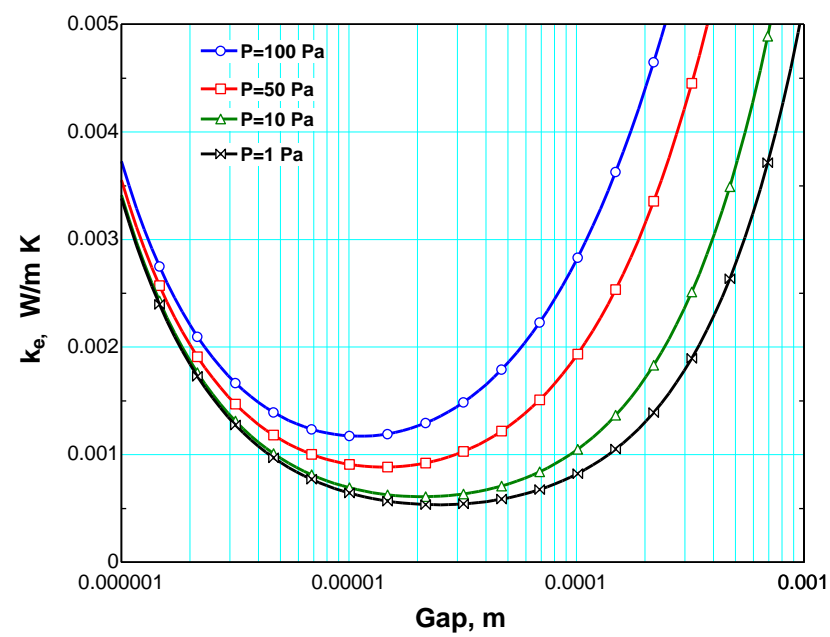

Figure 5 Effective thermal conductivity at different pressures of xenon gas and as a function of gap size, in an array of 40 shields

Increasing the gap makes the distance for the gas molecules longer. The flow regime changes from free molecular to transition, yielding an optimal gap size. As the gap is further widened, the flow regime of the gas varies to temperaturejump, and even to continuum, depending on the gas pressure. The lower the pressure, the smallest is the array conductivity, but grows up with the gap size above its optimum. The optimal gap size and the minimal array conductivity at this size are plotted in Figure 6, against the xenon gas pressure in the range of 0.01-100 Pa. It can be seen that the optimal gap is smaller at higher pressures, and conductivity increases with pressure.

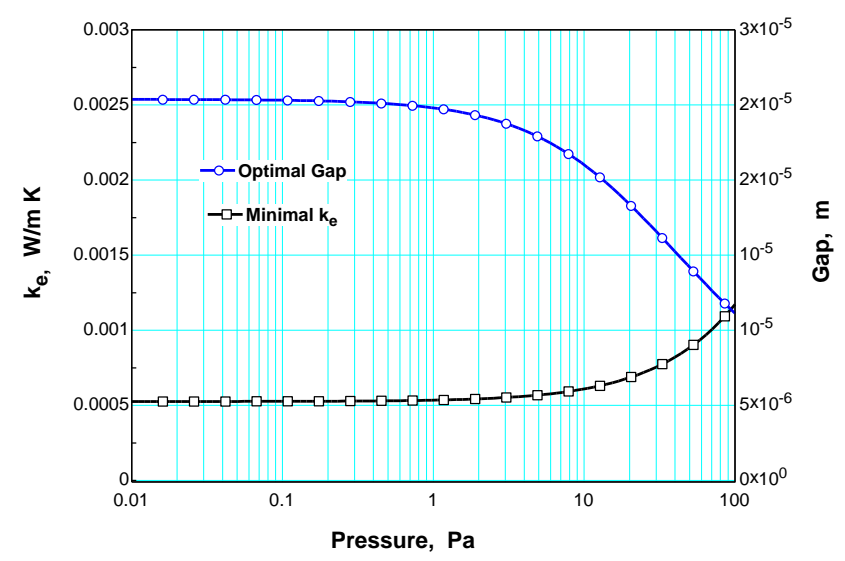

Figure 6 Effective thermal conductivity at an optimal gap and as a function of xenon gas pressure in an array of 40 shields

\section{EXPERIMENTAL SET-UP}

An experimental apparatus was designed and constructed for measurements of the effective thermal conductivity of the multi-foil insulation array, operated at steady state with different gases, at different gas pressures and temperatures [9].

The experimental apparatus is schematically presented in Figure 7. It consists of a test section, a rotary pump, a diffusion pump, and sensors for measurements and control.

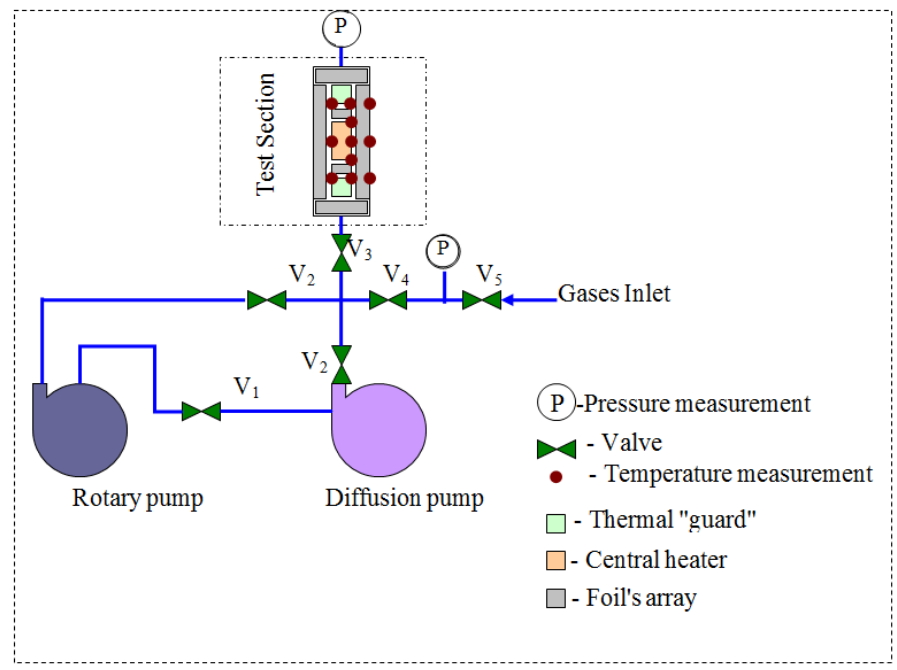

Figure 7 Sketch of the experimental set-up

A multi-foil array was constructed of stainless steel foils, $0.012 \mathrm{~mm}$ thick, spirally wrapped in 40 turns. Zirconium oxide particles, $50 \mu \mathrm{m}$ in diameter, were sprayed on one side of the foil, to serve for separation and mechanical support of the radiation shields. An external tube, $0.12 \mathrm{~mm}$ thick, served as an envelope of the array. The test section was connected to a vacuum system, which supplied the required gas pressure.

Inside the multi-foil array a stainless steel bar, $15 \mathrm{~mm}$ in outer diameter, was installed. Three heaters were mounted along the tube axis: central, upper and lower heater. The heat produced in the central heater had to be transferred radially only through the array of foils. Its effective length had to 
provide reliable measurements of the radial heat transfer rate. Therefore, the upper and lower heaters were operated as "thermal guards", to minimize axial heat losses. Discs for thermal insulation were also used in the axial gaps between the central heater and the "thermal guards". Temperature controllers were used to adjust the temperature of those heaters to the temperature of the central heater.

The thermocouples and the electric wires were installed axially along the array and the thermal guards. To reduce errors in temperature measurements, $\mathrm{Cr}-\mathrm{Al}$ pins were used at the connectors of the test section for the thermocouples wires. The thermocouples were of $\mathrm{K}$ type, ungrounded, 0.02 " in diameter, with 304ss sheet cover. Eight thermocouples were installed inside the heaters, as shown in Figure 7. Four thermocouples were mounted in the central heater: two at the edges, and two at the center, at opposite sides. Two thermocouples were installed in the upper heater, and two in the lower heater. Each, $1.5 \mathrm{~mm}$ from the edge of the central heater, and on opposite sides. Three thermocouples were fixed on the outer envelope of the test section, one at the center, and the other two $30 \mathrm{~mm}$ above and below the center. Grooves, $0.5 \mathrm{~mm}$ wide and $0.6 \mathrm{~mm}$ deep, were formed along the heaters for the thermocouples.

The measured temperature differences between the thermocouples were recorded with a resolution of $0.1^{\circ} \mathrm{C}$. The uncertainty in pressure measurements was up to $10 \%$. The uncertainty in the supplied power was 3\%. The emissivity of the shields, measured by a Raytek infra-red thermometer, was $\varepsilon=0.2$ with an uncertainty of $3 \%$.

The effective conductivity of particles is not easily assessed theoretically. It varies with the contact area particle - foil. The contact area depends both on the precise shape of the particle, as well as on the mechanical pressure exerted on the foil in the process of wrapping. Measurement of the particle conductivity accounts for both effects.

Some of the experiments performed in the above described apparatus, were used for calibration of the effective conductivity of particles, which is a parameter in the herein presented model.

Calibration of the conductivity of the $50 \mu \mathrm{m}$ zirconia particles was carried out in vacuum at pressures of $0.092 \mathrm{~Pa}$, 0.133 Pa, 0.373 Pa, 2.37 $\mathrm{Pa}$ and 4.5 Pa. Nitrogen was entrapped in the array, and the foils emissivity was 0.2 .

The experimental values of the array conductivity were introduced into the physical model, for calibration of the particles conductivity, which is dominant at those high vacuum conditions. A value of $2.13 \times 10^{-4} \mathrm{~W} / \mathrm{m} \mathrm{K}$ was obtained for the particles effective conductivity.

\section{RESULTS AND DISCUSSION}

The current study consists of an experimental investigation and a physical model of a cylindrical, radial, multi-foil array aimed for insulation. The experiments were performed at steady state. The interstitial gas in the array was xenon. All the measurements are summarized in Table 1.

11 experiments were conducted in xenon. The gas pressure applied was $1.01 \times 10^{4} \mathrm{~Pa}$, and $1.01 \times 10^{5} \mathrm{~Pa}$. The inside temperature ranged within $46^{\circ} \mathrm{C}-365^{\circ} \mathrm{C}$. The external temperature varied from $24^{\circ} \mathrm{C}$ up to $42^{\circ} \mathrm{C}$.

The effective thermal conductivities of the array, calculated from these experiments are shown in the last column of Table 1 , as $\mathrm{k}_{\mathrm{e}, \mathrm{exp}}$, with their errors.

Table 1. Experimental results

\begin{tabular}{ccccccc}
\hline No & $\mathrm{P}(\mathrm{Pa})$ & $\mathrm{T}_{\mathrm{h}}\left({ }^{\circ} \mathrm{C}\right)$ & $\mathrm{T}_{\mathrm{c}}\left({ }^{\circ} \mathrm{C}\right)$ & $\mathrm{T}_{\mathrm{av}}(\mathrm{K})$ & $\mathrm{q}(\mathrm{W})$ & $\mathrm{k}_{\text {e)exp }}(\mathrm{W} / \mathrm{m} \mathrm{K})$ \\
\hline 1 & $1.01 \mathrm{E}+05$ & 46 & 24.5 & 308.3 & 0.244 & $0.00816 \pm 0.00088$ \\
2 & $1.01 \mathrm{E}+05$ & 90 & 25.6 & 330.8 & 0.797 & $0.0089 \pm 0.00058$ \\
3 & $1.01 \mathrm{E}+05$ & 179 & 29.2 & 377.1 & 2.104 & $0.0101 \pm 0.0006$ \\
4 & $1.01 \mathrm{E}+05$ & 242 & 31.3 & 409.7 & 3.194 & $0.0109 \pm 0.0006$ \\
5 & $1.01 \mathrm{E}+05$ & 314.5 & 37.2 & 448.9 & 4.627 & $0.0120 \pm 0.0007$ \\
6 & $1.01 \mathrm{E}+04$ & 83 & 26 & 327.5 & 0.642 & $0.0081 \pm 0.0005$ \\
7 & $1.01 \mathrm{E}+04$ & 130 & 27.5 & 351.8 & 1.269 & $0.0089 \pm 0.0005$ \\
8 & $1.01 \mathrm{E}+04$ & 177 & 28.5 & 375.8 & 1.982 & $0.0096 \pm 0.0006$ \\
9 & $1.01 \mathrm{E}+04$ & 244 & 35.6 & 412.8 & 3.130 & $0.0108 \pm 0.0006$ \\
10 & $1.01 \mathrm{E}+04$ & 305 & 38.5 & 444.8 & 4.373 & $0.0118 \pm 0.0007$ \\
11 & $1.01 \mathrm{E}+04$ & 365.5 & 41.5 & 476.5 & 5.722 & $0.0127 \pm 0.0007$
\end{tabular}

The modeled curves are based on calculated gas conductivities, on the calibrated conductivity of the $50 \mu \mathrm{m}$ zirconia particles, $2.13 \times 10^{-4} \mathrm{~W} / \mathrm{m} \mathrm{K}$, and on the radiative conductivity between stainless steel foils, of an emissivity of 0.2 , in an array of 40 foils, $12 \mu \mathrm{m}$ thick.

We notice that at the thermal conductivity of the array in nitrogen, reaches at atmospheric pressure up to $5 \times 10^{-2} \mathrm{~W} / \mathrm{m} \mathrm{K}$ as presented in Figure 2. In helium at atmospheric pressure, the conductivity of the array is much higher than in nitrogen, e.g. $0.25 \mathrm{~W} / \mathrm{m} \mathrm{K}$. In xenon, at atmospheric pressure, the effective thermal conductivity of the array is considerably lower than in nitrogen or helium. Thus, the measured conductivity decreases down to $8.16 \times 10^{-3} \mathrm{~W} / \mathrm{m} \mathrm{K}$ as presented in Table 1 .

Figure 8 , demonstrates the experimental and modeled conductivities in xenon, at a scale of $0-0.014 \mathrm{~W} / \mathrm{m} \mathrm{K}$, within the pressure range of $0.01-1 \times 10^{5} \mathrm{~Pa}$. The modeled curves are continuous for the temperature range of $300-500 \mathrm{~K}$, at steps of $50 \mathrm{~K}$. The measurements were performed at distinct pressures of $1 \times 10^{4} \mathrm{~Pa}$ and $1 \times 10^{5} \mathrm{~Pa}$, and at specified temperatures. All the measured conductivities are higher than the predicted values. At $1 \times 10^{4} \mathrm{~Pa}$, the conductivity measured at $327 \mathrm{~K}$ is $8.1 \times 10^{-3}$ $\mathrm{W} / \mathrm{m} \mathrm{K}$, while the model presents a value of $7.5 \times 10^{-3} \mathrm{~W} / \mathrm{m} \mathrm{K}$, showing a deviation of $7.5 \%$. At $476 \mathrm{~K}$, the measured conductivity is $0.0127 \mathrm{~W} / \mathrm{m} \mathrm{K}$, as compared to the modeled one of $0.011 \mathrm{~W} / \mathrm{m} \mathrm{K}$, deviating by $13-14 \%$.

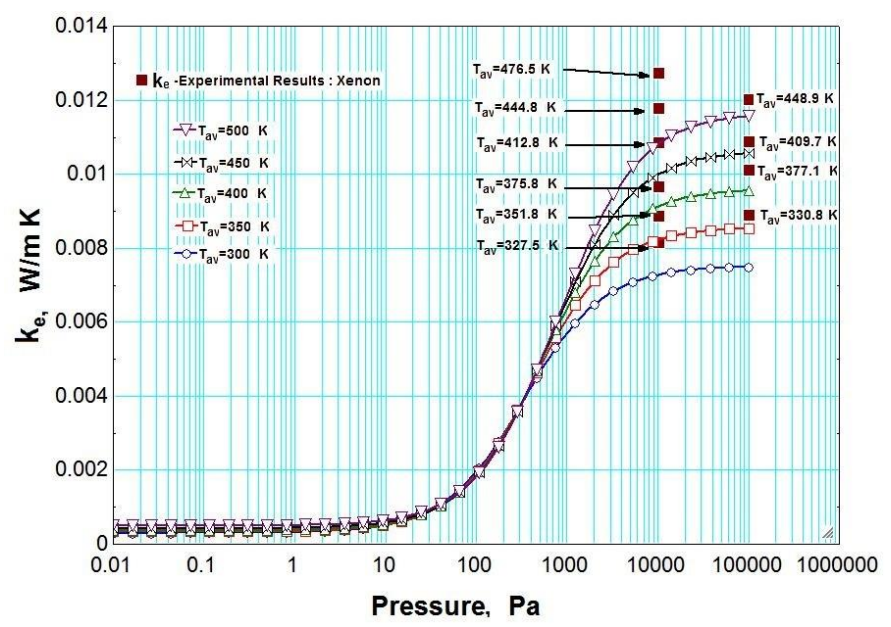

Figure 8 Effective thermal conductivity at different average temperature and as a function of xenon gas pressure 
At $1 \times 10^{5} \mathrm{~Pa}$ and $308 \mathrm{~K}$ the measurement yields $8.16 \times 10^{-3}$ $\mathrm{W} / \mathrm{m} \mathrm{K}$, and the prediction provides $7.56 \times 10^{-3} \mathrm{~W} / \mathrm{m} \mathrm{K}$, deviating $7.5 \%$. At the same pressure and at $448 \mathrm{~K}$, the experimental result is $1.2 \times 10^{-2} \mathrm{~W} / \mathrm{m} \mathrm{K}$, while the theoretical value is only $1.05 \times 10^{-2} \mathrm{~W} / \mathrm{m} \mathrm{K}$, deviating by $12 \%$.

Apparently the agreement between the experimental and modeled effective thermal conductivities of the array, within 0$15 \%$, is obtained in the pressure range of $1 \times 10^{4} \mathrm{~Pa}-1 \times 10^{5} \mathrm{~Pa}$.

\section{CONCLUSIONS}

This study presents experimental work and parametric study, for assessing and measuring effective thermal conductivity of a cylindrical multi-foil array, with xenon at pressures of $0.01-10^{5} \mathrm{~Pa}$ and in temperature range of $20-500^{\circ} \mathrm{C}$.

In the physical model the thermal conductivity of the array was calculated by summing up radiation, gas conduction and particles conduction at steady state. An experimentally validated model [9] was used for the analysis.

The measured effective thermal conductivities of the array ranged in xenon within $8.1 \times 10^{-3}-1.27 \times 10^{-2} \mathrm{~W} / \mathrm{m} \mathrm{K}$.

Good comparison was achieved between the predicted and measured conductivities of the array with xenon gas.

Near atmospheric pressure the effective thermal conductivity of the MFI array with xenon is lower than conventional thermal insulations.

The ratio between the total thickness of the stainless steel shields with the outer envelope and the total thickness of the insulation array has a great effect on the total effective thermal conductivity of the insulation array. The effect of the thickness of the outer envelope became insignificant with large number of shields.

The present combination of modeling and experimentation could be used for parametric investigations and optimizations of multi-foil arrays, and in particular for the design of compact, effectively controlled insulations by controlling gas type and pressure in a variety of thermal management applications.

\section{REFERENCES}

[1] Paquin, M.L., High Temperature Multi-foil Thermal Insulation, Proceedings of Intersociety Energy Conversion Engineering Conference, 1968, pp. 256-262.

[2] Paquin, M.L., The multi-foil thermal insulation development program, Proceedings of the $4^{\text {th }}$ Intersociety Energy Conversion Engineering Conference, 1969, pp. 408-415.

[3] DeWitt, W.D., Gibbon, N.C., Reid, R.L., Multi-Foil Type Thermal Insulation, IEEE Transactions on Aerospace and Electronic Systems, Vol. 4, No.5, 1968, pp. 263-271.

[4] Keller, K., Hoffmann, M., Zorner, W., Blumenberg, J., Application of high temperature multilayer insulation, Acta Astronautica, Vol. 26, No. 6, 1992, pp. 451-458.

[5] Kang, C.S., Hinton, J.F., McNamara, R.C., Heat Transfer through a Multifoil Insulation System by Radiation and Gaseous ConductionAnalytical and Experimental Investigation. In: $27^{\text {th }}$ AIAA Aerospace Sciences Meeting, 1989.

[6] Stauffer, T., Jog, M., Ayyaswamy, P., The Effective Thermal Conductivity of Multi Foil Insulation as a Function of Temperature and Pressure, AIAA Paper 92-2939, 1992.

[7] Beskok, A., Validation of a new velocity-slip model for separated gas microflows. Numerical Heat Transfer: Part B: Fundamentals, Vol. 40, No. 6, 2001, pp. 451-471.

[8] Incropera, F. P., De Witt, D. P., Fundamentals of Heat and Mass Transfer, Wiley, New York, 1990, p. 559.

[9] Haim, Y., Weiss, Y., Letan, R., Effect of Spacers on the Thermal Performance of an Annular Multilayer Insulation, Applied Thermal Engineering, Vol. 65, 2014, pp. 418-421.

[10] Swift, J. D., Kinetic Theory of gases and gaseous flow, in: A.H. Beck (Ed.), Handbook of Vacuum Physics, Vol. 1, No. 5, Pergamon Press, 1966, pp. 229-319.

[11] Kaganer, M.G., Thermal insulation in cryogenic engineering, Israel Program for Scientific Translations, 1969, pp 3-7. 